CLINICAL STUDY

\title{
Corticotrope hypersecretion coupled with cortisol hypo-responsiveness to stimuli is present in patients with autoimmune endocrine diseases: evidence for subclinical primary hypoadrenalism?
}

Roberta Giordano, Marcella Balbo, Andreea Picu, Lorenza Bonelli, Rita Berardelli, Alberto Falorni ${ }^{1}$, Ezio Ghigo and Emanuela Arvat

Division of Endocrinology and Metabolism, Department of Internal Medicine, University of Turin, Ospedale Molinette, C.so Dogliotti 1410126 Turin, Italy and ${ }^{1}$ Department of Internal Medicine, University of Perugia, Perugia, Italy

(Correspondence should be addressed to E Arvat; Email: emanuela.arvat@unito.it)

\begin{abstract}
Objective: In autoimmune polyglandular syndrome types 1, 2, and 4 primary adrenal insufficiency is present, but its diagnosis is often late. We investigated the function of the hypothalamic-pituitaryadrenal axis in a group of patients with autoimmune diseases (AP) without any symptoms and signs of hypoadrenalism.

Design: In 10 AP and 12 normal subjects (NS), we studied cortisol (F), aldosterone (A), and DHEA responses to $0.06 \mu \mathrm{g}$ adrenocorticotropin (ACTH) (1-24) followed by $250 \mu \mathrm{g}$, ACTH and F responses to human corticotropin-releasing hormone (hCRH; $100 \mu \mathrm{g}$ ) and insulin tolerance test (ITT) $(0.1 \mathrm{UI} / \mathrm{kg})$. Results: Basal F, A, DHEA, as well as urinary free cortisol and plasma renin activity levels in AP and NS were similar, whereas ACTH levels in AP were higher $(P<0.05)$ than in NS. NS showed F, A, and DHEA response to both consecutive ACTH doses. In AP, the F, A, and DHEA responses to $250 \mu \mathrm{g}$ ACTH were similar to those in NS, whereas the $0.06 \mu \mathrm{g}$ ACTH dose did not elicit any significant response. The ACTH responses to hCRH and ITT in AP were higher $(P<0.05)$ than in NS. The F response to hCRH in AP was lower $(P<0.05)$ than in NS, whereas the F response to ITT in AP did not significantly differ from NS.

Conclusions: Enhancement of both basal and stimulated corticotrope secretion coupled with reduced adrenal sensitivity to low ACTH dose is present in AP patients without symptoms and signs of hypoadrenalism. This functional picture suggests that normal adrenal secretion is maintained due to corticotrope hyperfunction, suggesting the existence of some subclinical primary hypoadrenalism.
\end{abstract}

European Journal of Endocrinology 155 421-428

\section{Introduction}

Autoimmune polyglandular syndromes (APS) are rare diseases that are classified into four constellations based on the clinical clustering of the various components (1-4). In APS types 1, 2, and 4, primary adrenal insufficiency is usually present, but its diagnosis is often late because it is difficult to demonstrate in a subclinical phase $(3,4)$. In the early phase, APS patients generally show at least one clinical disease characteristic of the syndrome with one or more biochemical markers of the other components coupled with normal function of the target organs (1-4). Among the biochemical markers, detection of circulating adrenal autoantibodies against the steroidogenetic enzyme 21-hydroxylase (210HAb) is the most commonly used enzyme for the early identification of patients at risk of developing an autoimmune primary adrenal insufficiency (5-8). It is assumed that the first sign of primary adrenal insufficiency in its natural history is usually represented by an increase of plasma renin activity (PRA) levels associated with low-normal or low aldosterone levels; afterwards, adrenocorticotropin (ACTH) levels increase and a low cortisol response to ACTH becomes evident. Finally, low cortisol and urinary cortisol levels coupled with highly elevated ACTH levels demonstrate overt adrenal insufficiency (9). The administration of synthetic ACTH is the classical test to evaluate adrenal function and it has been proposed for the diagnosis of both primary and secondary hypoadrenalism (10-14). Although the dose of $250 \mu \mathrm{g} \mathrm{ACTH}$ is classically used in this goal, it has clearly been demonstrated that it is a very supra-maximal dose eliciting extremely supra-physiological circulating ACTH levels (10-14). Therefore, the ACTH test has been proposed with 
lower doses and the most extensively investigated has been the $1 \mu \mathrm{g}$ ACTH dose (10-15). However, it has been demonstrated that $0.06 \mu \mathrm{g}$ is one of the lowest and effective stimulatory doses to test adrenal function (16). In previous studies, we proposed to study the adrenal response by administering two consecutive ACTH doses, i.e. $0.06 \mu \mathrm{g}$ followed by $250 \mu \mathrm{g}$ ACTH, in order to first evaluate the adrenal sensitivity to very low corticotropin exposure and then the adrenal response to the exposure to the supra-maximal ACTH dose (16). Indeed, in a group of patients with autoimmune diseases tested with this approach, we were able to demonstrate the loss of adrenal sensitivity to the lowest ACTH dose despite normal cortisol and DHEA response to the $250 \mu \mathrm{g}$ ACTH dose, coupled with basal ACTH levels higher than in normal subjects (NS) (17). These findings suggested the hypothesis that some adrenal impairment was already present in these patients despite the absence of any other signs and symptoms of hypoadrenalism. Based on this, we decided to investigate further the function of the hypothalamic-pituitary-adrenal (HPA) axis in patients with autoimmune diseases (AP), in order to verify whether the functional HPA profile would suggest the existence of some subclinical hypoadrenalism. To this goal, in a new cohort of AP patients without any symptoms and signs of overt hypocortisolism, we studied the adrenal responsiveness to ACTH as well as the ACTH and cortisol responses to classical stimuli of the HPA axis such as human corticotropin-releasing hormone (hCRH) and insulin-induced hypoglycemia. Our working hypothesis was to verify whether these patients are also connoted by enhancement of both basal and stimulated corticotrope secretion, possibly coupled with impairment of the adrenal response to these stimulations.

\section{Subjects and methods}

\section{Drugs}

Vials containing $250 \mu \mathrm{g}$ ACTH (ACTH(1-24), tetracosactin, Synacthen) were purchased from NovartisPharma (Huningue, France). The ACTH $250 \mu \mathrm{g}$ dose was prepared by adding $250 \mu \mathrm{g}$ to $2 \mathrm{ml}$ sterile saline solution. For the ACTH $0.06 \mu \mathrm{g}$ dose, $250 \mu \mathrm{g}$ was diluted in a bottle containing $250 \mathrm{ml}$ sterile saline solution and mixed thoroughly; $1 \mathrm{ml}$ of this prepared solution containing $1 \mu \mathrm{g}$ ACTH was added to $9 \mathrm{ml}$ saline; then we took $0.6 \mathrm{ml}$ and added saline to obtain $1 \mathrm{ml}$ volume; the resulting solution was used immediately after preparation. Vials containing $100 \mu \mathrm{g} \mathrm{hCRH}$ were purchased from Ferring (Kiel, Germany). Vials containing 1000 UI of regular insulin (Actrapid) were purchased from Novo Nordisk A/S (Bagsværd, Denmark).

\section{Study protocol}

Ten patients with at least two autoimmune diseases, without any clinical signs and symptoms of overt hypoadrenalism (AP; $2 \mathrm{M}$ and $8 \mathrm{~F}$, age $22-45$ years, body mass index (BMI) $22-25 \mathrm{~kg} / \mathrm{m}^{2}$ ) and 12 normal age- and BMI-matched subjects (NS; $6 \mathrm{M}$ and $6 \mathrm{~F}$, age 22-34 years, BMI $20-25 \mathrm{~kg} / \mathrm{m}^{2}$ ) were studied. The group of AP patients is totally different from that reported in our previous paper (17). On the other hand, the data in NS are the same as those already published $(16,17)$ and are used herein as the control group. Clinical details of the patients are reported in Table 1.

Table 1 Clinical features and basal hormonal values of patients with autoimmune diseases (AP) and basal hormonal values in normal subjects (NS).

\begin{tabular}{|c|c|c|c|c|c|c|c|c|c|}
\hline Patients & Sex & $\begin{array}{c}\text { Age } \\
\text { (years) }\end{array}$ & Diseases & $\begin{array}{l}\text { ACTH } \\
(\mathrm{pg} / \mathrm{ml})\end{array}$ & $\underset{(\mu \mathrm{g} / \mathrm{l})}{\mathbf{F}}$ & $\begin{array}{c}\text { A } \\
(\mathrm{pg} / \mathrm{ml})\end{array}$ & $\begin{array}{c}\text { DHEA } \\
(\mu \mathrm{g} / \mathrm{l})\end{array}$ & $\begin{array}{c}\text { PRA } \\
\text { (ng/ml per h) }\end{array}$ & $\begin{array}{c}\text { UFC } \\
(\mu \mathrm{g} / 24 \mathrm{~h})\end{array}$ \\
\hline \multicolumn{10}{|l|}{ AP } \\
\hline 1 & $\mathrm{~F}$ & 32 & HYPOTH, VIT & 49.8 & 129.6 & 133.2 & 12.3 & 0.6 & 44.0 \\
\hline 2 & $\mathrm{~F}$ & 42 & POF, BD & 36.4 & 187.2 & 105.4 & 7.9 & 0.1 & 30.0 \\
\hline 3 & $\mathrm{~F}$ & 43 & HYPOTH, AL & 46.2 & 142.3 & 225.1 & 14.0 & 0.2 & 38.0 \\
\hline 4 & $\mathrm{~F}$ & 29 & HYPOTH, POF & 40.1 & 125.5 & 164.2 & 15.0 & 0.5 & 56.0 \\
\hline 5 & $\mathrm{~F}$ & 40 & HYPOTH, POF, CAG & 42.8 & 110.9 & 188.1 & 3.2 & 0.5 & 38.0 \\
\hline 6 & $\mathrm{~F}$ & 39 & HYPOTH, POF & 46.6 & 121.2 & 135.4 & 6.8 & 0.3 & 41.0 \\
\hline 7 & $\mathrm{~F}$ & 27 & HYPOPTH, POF, RD & 45.4 & 130.4 & 177.3 & 10.1 & 2.2 & 30.0 \\
\hline 8 & $\mathrm{~F}$ & 45 & HYPOTH, POF & 50.7 & 127.5 & 158.6 & 8.4 & 0.3 & 34.0 \\
\hline 9 & M & 32 & HYPOTH, CAG & 28.4 & 149.3 & 195.0 & 12.5 & 0.9 & 90.0 \\
\hline 10 & $M$ & 22 & HYPOTH, VIT & 26.2 & 110.9 & 107.5 & 18.7 & 0.1 & 45.0 \\
\hline Mean & & & & $41.3^{\star}$ & 133.5 & 159.0 & 10.9 & 0.6 & 44.6 \\
\hline S.E.M. & & & & 2.7 & 7.1 & 12.3 & 1.4 & 0.2 & 5.6 \\
\hline \multicolumn{10}{|l|}{ NS } \\
\hline Mean & & & & 18.7 & 135.7 & 144.7 & 8.2 & 1.1 & 61.8 \\
\hline S.E.M. & & & & 1.8 & 12.4 & 12.9 & 0.9 & 0.2 & 11.3 \\
\hline
\end{tabular}

${ }^{*} P<0.05$ vs NS. AL, Alopecia; BD, Basedow's disease; CAG, chronic atrophic gastritis; HYPOTH, hypothyroidism; VIT, vitiligo; POF, precocious ovary failure; $\mathrm{RD}$, rheumatic disease; $\mathrm{CD}$, celiacdisease. $\mathrm{ACTH}$, adrenocorticotropin $(0.22 \mathrm{pg} / \mathrm{ml}=1 \mathrm{pmol} / \mathrm{l}) ; \mathrm{F}$, cortisol $(2.7 \mu \mathrm{g} / \mathrm{l}=1 \mathrm{nmol} / \mathrm{l}) ; \mathrm{A}$, aldosterone $(2.7 \mathrm{pg} / \mathrm{ml}=$ $1 \mathrm{pmol} / \mathrm{l})$; DHEA $(3.4 \mu \mathrm{g} / \mathrm{l}=1 \mathrm{nmol} / \mathrm{l})$; PRA, plasma renin activity $(0.27 \mathrm{ng} / \mathrm{ml} \mathrm{per} \mathrm{h}=1 \mathrm{ng} /(\mathrm{I} \times \mathrm{s}))$; UFC, urinary free cortisol $(2.75 \mu \mathrm{g} / 24 \mathrm{~h}=1 \mathrm{nmol} / \mathrm{d})$. 
Table 2 Cortisol $(F)$, aldosterone (A) and DHEA responses (peaks and change in areas under the response curve ( $\triangle A$ AUC), mean \pm s.E.M.) after 0.06 or $250 \mu \mathrm{g} \mathrm{ACTH(1-24)} \mathrm{doses} \mathrm{in} \mathrm{patients} \mathrm{with} \mathrm{autoimmune} \mathrm{diseases} \mathrm{(AP)} \mathrm{and} \mathrm{in} \mathrm{normal} \mathrm{subjects} \mathrm{(NS).}$

\begin{tabular}{|c|c|c|c|}
\hline & F peak $(\mu \mathrm{g} / \mathrm{l})$ & A peak $(p g / m l)$ & DHEA peak $(\mu \mathrm{g} / \mathrm{l})$ \\
\hline \multicolumn{4}{|l|}{ AP } \\
\hline $0.06 \mu \mathrm{g}$ АCTH & $152.3 \pm 21.1^{*}$ & $137.9 \pm 29.3^{*}$ & $10.1 \pm 1.4^{*}$ \\
\hline $250 \mu \mathrm{g}$ ACTH & $229.4 \pm 21.3$ & $214.6 \pm 25.4$ & $18.3 \pm 2.0$ \\
\hline \multicolumn{4}{|l|}{ NS } \\
\hline $0.06 \mu \mathrm{g}$ АCTH & $197.8 \pm 9.5$ & $207.2 \pm 12.0$ & $12.8 \pm 1.1$ \\
\hline \multirow[t]{2}{*}{$250 \mu \mathrm{g} \mathrm{ACTH}$} & $279.4 \pm 12.2$ & $272.1 \pm 21.1$ & $18.5 \pm 2.0$ \\
\hline & $\Delta$ FAUC $(\mu \mathrm{g} / \mathrm{l}$ per $\mathrm{h})$ & 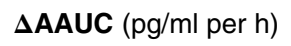 & $\triangle$ DHEAAUC $(\mu \mathrm{g} / \mathrm{l}$ per $\mathrm{h})$ \\
\hline \multicolumn{4}{|l|}{ AP } \\
\hline $0.06 \mu \mathrm{g}$ ACTH & $24.7 \pm 431.1^{*}$ & $-1223.1 \pm 1108.1^{*}$ & $-3.0 \pm 8.7^{\star}$ \\
\hline $250 \mu \mathrm{g} \mathrm{ACTH}$ & $4308.5 \pm 475.7$ & $5022.2 \pm 895.9$ & $376.7 \pm 50.5$ \\
\hline \multicolumn{4}{|l|}{ NS } \\
\hline $0.06 \mu \mathrm{g}$ АСТН & $1783.8 \pm 322.4$ & $1046.3 \pm 389.7$ & $79.8 \pm 32.5$ \\
\hline $250 \mu \mathrm{g} \mathrm{ACTH}$ & $4864.9 \pm 402.0$ & $5812.6 \pm 952.6$ & $406.1 \pm 59.6$ \\
\hline
\end{tabular}

${ }^{*} P<0.05$ vs NS.

All subjects gave their informed consent to participate in the study, which had been approved by the independent Ethical Committee of the University of Turin. All subjects received the following treatments in random order at least 5 days apart: (a) ACTH(1-24) $0.06 \mu \mathrm{g}$ i.v. (at $0 \mathrm{~min}$ ) followed by $\operatorname{ACTH}(1-24) 250 \mu \mathrm{g}$ i.v. (at + $60 \mathrm{~min}$ ); (b) hCRH $100 \mu \mathrm{g}$ i.v. (at $0 \mathrm{~min}$ ); (c) insulin tolerance test (ITT) $0.1 \mathrm{UI} / \mathrm{kg}$ i.v. (at $0 \mathrm{~min}$ ); in testing session (c) plasma glucose levels were also assayed at baseline and at each time point. All the normal women and AP patients without premature ovarian failure (POF) were studied in their early follicular phase, while patients with POF were not in hormone replacement therapy at the time of the study. Patients with hypothyroidism and Basedow's disease were under appropriate treatment with L-thyroxine or methimazole at the time of the study, leading to normal thyroidstimulating hormone, fT3, and fT4 levels. Patients with rheumatic disease had not been under steroid treatment for at least 1 year and the previous treatment included immunosuppressive steroid doses. In AP patients, as well as in NS blood samples for ACTH, PRA, and urinary samples for urinary free cortisol (UFC) were collected at baseline; during testing session (a) blood samples for cortisol (F), aldosterone (A), and DHEA assay were collected at baseline ( $0 \mathrm{~min}$ ) and then at 15, 30, 60, 90, and $120 \mathrm{~min}$; during testing sessions (b) and (c) blood samples for ACTH and F assay were collected at baseline and then at 15, 30, 45, 60, 75, and $90 \mathrm{~min}$. All tests were performed in the morning starting at 0830$0900 \mathrm{~h}$ after an overnight fasting and $30 \mathrm{~min}$ after venous cannulation kept patent by slow infusion of isotonic saline.

The patients were also evaluated for the presence of circulating adrenal autoantibodies against the steroidogenetic enzyme 21-hydroxylase (210HAb); none of the patients displayed positivity for 210HAb (210HAb index <0.06). Serum cortisol levels $(\mu \mathrm{g} / \mathrm{l} ; 2.7 \mu \mathrm{g} / \mathrm{l}=$ $1 \mathrm{nmol} / \mathrm{l}$ ) were measured in duplicate by RIA
(CORT-CTK125; Diasorin Diagnostic, Saluggia, Italy). The sensitivity of the assay was $11.0 \mu \mathrm{g} / \mathrm{l}$; the inter- and intra-assay coefficients of variation $(\mathrm{CV})$ ranged from 4.3 to $14.6 \%$ and from 4.2 to $8.96 \%$ respectively. Serum aldosterone levels $(\mathrm{pg} / \mathrm{ml} ; 2.7 \mathrm{pg} / \mathrm{ml}=1 \mathrm{pmol} / \mathrm{l})$ were measured in duplicate by RIA (ALDO-MAIA; Biochem Diagnostic, Guidonia, Italy). The sensitivity of the assay was $16.2 \mathrm{pg} / \mathrm{ml}$; the inter- and intra-assay CV ranged from 11.96 to $14.06 \%$ and from 4.21 to $9.57 \%$ respectively. Serum DHEA levels $(\mu \mathrm{g} / \mathrm{l} ; 3.4 \mu \mathrm{g} / \mathrm{l}=$ $1 \mathrm{nmol} / \mathrm{l}$ ) were measured in duplicate by RIA (DSL9000 ACTIVE DHEA, Diagnostic Systems Laboratories, Inc., Webster, TX, USA). The sensitivity of the assay was $0.068 \mu \mathrm{g} / \mathrm{l}$; the inter- and intra-assay $\mathrm{CV}$ ranged from 5.6 to $10.6 \%$ and from 7.0 to $10.2 \%$ respectively. Plasma ACTH levels (pg/ml; $0.22 \mathrm{pg} / \mathrm{ml}=1 \mathrm{pmol} / \mathrm{l})$ were measured in duplicate by IRMA (Allegro HS-ACTH, IRMA, Nichols Institute Diagnostic, San Juan Capistrano, CA, USA). The sensitivity of the assay was $0.22 \mathrm{pg} / \mathrm{ml}$; the inter- and intra-assay CV ranged from 2.4 to $8.5 \%$ and from 3.9 to $9.9 \%$ respectively. PRA levels $(\mathrm{ng} / \mathrm{ml}$ per $\mathrm{h} ; 0.27 \mathrm{ng} / \mathrm{ml}$ per $\mathrm{h}=1 \mathrm{ng} /(\mathrm{l} \times \mathrm{s}))$ were measured in duplicate by RIA (RENCTK; Diasorin Diagnostic, Saluggia, Italy). The sensitivity of the assay was $0.2 \mathrm{ng} / \mathrm{ml}$ per $\mathrm{h}$; the interand intra-assay CV ranged from 9.27 to $21.12 \%$ and from 5.2 to $9.2 \%$ respectively. UFC levels $(\mu \mathrm{g} / 24 \mathrm{~h}$; $2.75 \mu \mathrm{g} / 24 \mathrm{~h}=1 \mathrm{nmol} / \mathrm{d}$ ) were measured in duplicate by RIA (Cortisol Bridge; Biochem Immunosystems Company, Milan, Italy). The sensitivity of the assay was $2.67 \mu \mathrm{g} / 24 \mathrm{~h}$; the inter- and intra-assay CV ranged from 3.98 to $5.75 \%$ and from 2.64 to $8.67 \%$ respectively. Plasma glucose levels $(\mathrm{mg} / \mathrm{dl}$; $0.05 \mathrm{mg} / \mathrm{dl}=1 \mathrm{mmol} / \mathrm{l}$ ) were measured by glucoseoxidase colorimetric method (Menarini Diagnostic, Florence, Italy). The 210HAb levels were determined in a radio-binding assay that uses in vitro translated recombinant human 35S-210H. The 210HAb levels were expressed as a relative index $(210 \mathrm{H}$ index $)$ based 
on the analysis of one positive and two negative standard sera included in each assay.

\section{Statistical analysis}

The results are expressed as mean \pm s.E.M. of either absolute hormonal levels or change in areas under the response curve $(\Delta \mathrm{AUC})$, calculated by trapezoidal integration. The statistical analysis was carried out using non-parametric ANOVA (Kruskal-Wallis) and then Wilcoxon matched pairs test or Mann-Whitney $U$-test as appropriate. Differences with $P$ value less than 0.05 were considered statistically significant.

\section{Results}

Basal F, A, DHEA as well as UFC and PRA levels in AP and NS were similar, whereas basal ACTH levels in AP were higher $(P<0.05)$ than in NS (Table 1$)$. NS showed
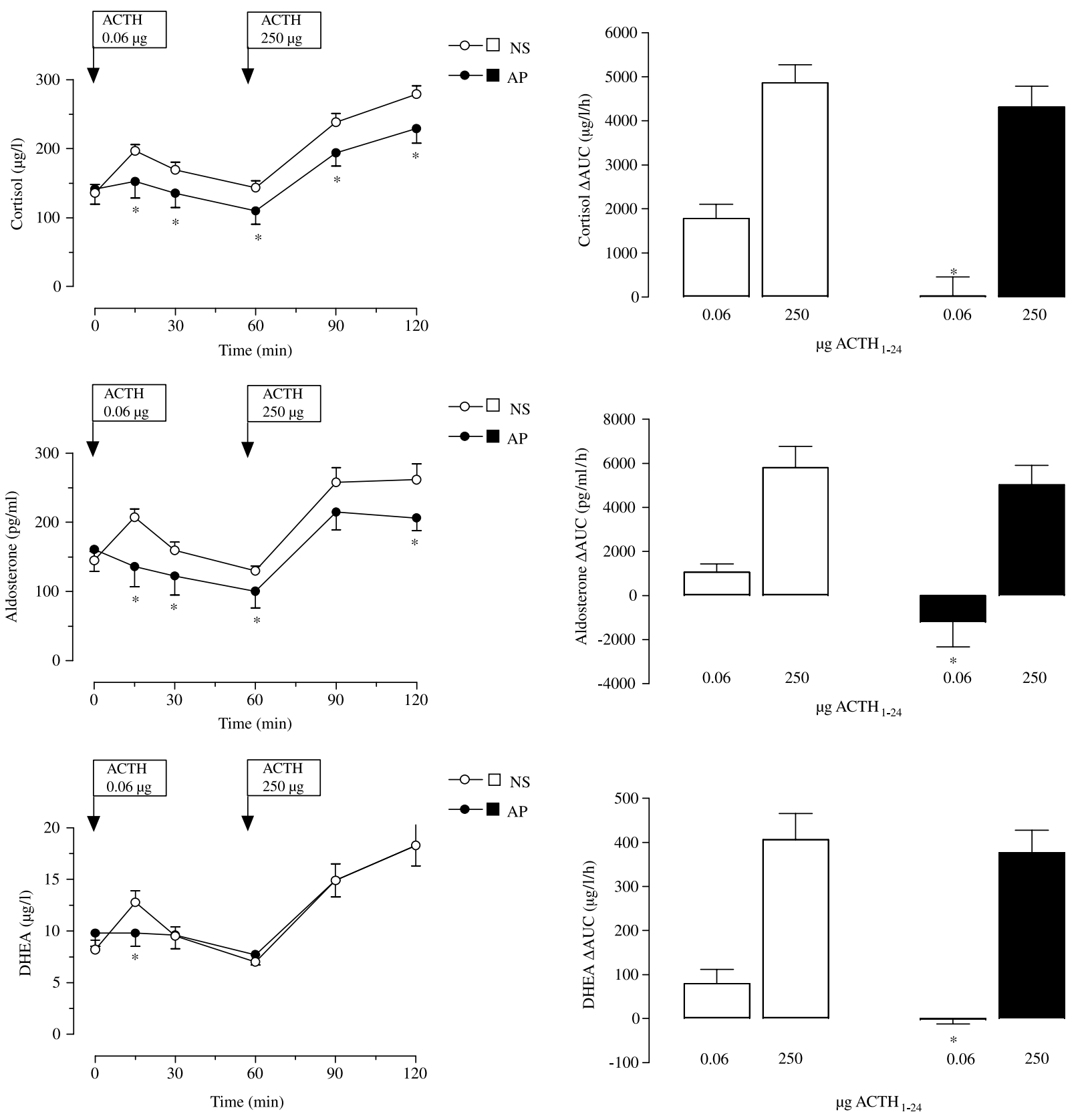

Figure 1 Mean ( \pm S.E.M.) cortisol, aldosterone, and DHEA levels and $\triangle$ AUCs after 0.06 followed by $250 \mu g$ ACTH doses in patients with autoimmune diseases (AP) and normal subjects (NS). ${ }^{*} P<0.05$ vs NS. 
F, A, and DHEA response to both consecutive ACTH doses; the hormonal responses were dose-dependent (Table 2, Fig. 1). In AP, the F, A, and DHEA responses to the second ACTH bolus, that is, the supra-maximal dose, were similar to those recorded in NS. However, the first ACTH dose of $0.06 \mu \mathrm{g}$ did not elicit any significant response of $\mathrm{F}, \mathrm{A}$, and DHEA in $\mathrm{AP}$ at variance with that observed in NS (Table 2, Fig. 1). Considering that the lowest cortisol increase to $0.06 \mu \mathrm{g}$ ACTH in NS was $143.6 \mu \mathrm{g} / \mathrm{l}$, four out of ten AP showed a cortisol peak above this value (data not shown).

ITT induced hypoglycemia (plasma glucose levels below $45 \mathrm{mg} / \mathrm{dl}$ with mean timing of occurrence of glucose nadir at $+30 \mathrm{~min}$ ) in both AP and NS (data not shown). Either hCRH or ITT elicited ACTH responses in AP clearly higher $(P<0.05)$ than those recorded in NS (Table 3, Figs 2 and 3). AP also showed an $\mathrm{F}$ response to hCRH lower $(P<0.05)$ than that in NS. On the other hand, the F response to ITT in AP did not significantly differ from that in NS (Table 3, Figs 2 and 3).

\section{Side effects}

No side effect was recorded during ACTH testing sessions in each group, whereas hCRH induced transient facial flushing in all subjects. Both patients and controls experienced classical hypoglycemic symptoms (hunger, sweating, tremor, restlessness, and palpitation) in ITT testing session. No medication was required and no test had to be stopped.

\section{Discussion}

The results of the present study demonstrate that patients with autoimmune diseases without any

Table 3 Adrenocorticotropin (ACTH) and cortisol (F) responses (peaks and change in areas under the response curve ( $\triangle A U C)$, mean \pm S.E.M.) after human corticotropin-releasing hormone (hCRH) $(100 \mu \mathrm{g}$ i.v. $)$ or insulin tolerance test (ITT) $(0.1 \mathrm{UI} / \mathrm{kg}$ i.v.) in patients with autoimmune diseases (AP) and in normal subjects (NS).

\begin{tabular}{|c|c|c|}
\hline & ACTH peak (pg/ml) & F peak $(\mu \mathrm{g} / \mathrm{l})$ \\
\hline \multicolumn{3}{|l|}{ AP } \\
\hline $\mathrm{hCRH}$ & $76.1 \pm 11.4^{\star}$ & $165.1 \pm 5.9$ \\
\hline ITT & $277.6 \pm 42.5^{\star}$ & $240.5 \pm 24.8$ \\
\hline \multicolumn{3}{|l|}{ NS } \\
\hline hCRH & $39.4 \pm 4.2$ & $179.5 \pm 12.2$ \\
\hline \multirow[t]{2}{*}{ ITT } & $109.6 \pm 8.5$ & $199.9 \pm 20.1$ \\
\hline & $\triangle$ ACTHAUC $(p g / m l$ per $h)$ & $\Delta$ FAUC $(\mu \mathrm{g} / \mathrm{l}$ per $\mathrm{h})$ \\
\hline \multicolumn{3}{|l|}{ AP } \\
\hline $\mathrm{hCRH}$ & $2373.5 \pm 501.1^{*}$ & $1412.7 \pm 754.6^{*}$ \\
\hline ITT & $10551.1 \pm 1946.2^{*}$ & $4411.7 \pm 1134.1$ \\
\hline \multicolumn{3}{|c|}{ ש. } \\
\hline hCRH & $1072.5 \pm 181.6$ & $4228.1 \pm 839.1$ \\
\hline ITT & $3592.0 \pm 851.7$ & $4125.0 \pm 709.3$ \\
\hline
\end{tabular}

${ }^{*} P<0.05$ vs NS. apparent symptoms and signs of hypoadrenalism, have normal basal adrenal hormone levels but are connoted by the loss of adrenal responsiveness to a very low ACTH dose coupled with enhancement of both basal and stimulated corticotrope secretion. Moreover, these patients also show a reduced cortisol response to hCRH. Primary adrenal insufficiency can be present in APS types 1,2, and 4, but its diagnosis is often delayed because it is difficult to show it in a subclinical phase (3, 4). The studies regarding the most appropriate method to diagnose a subclinical adrenal insufficiency are controversial. The ACTH test is a classical diagnostic approach; however, as testing with $250 \mu \mathrm{g}$ ACTH is fairly supra-maximal, lower ACTH doses have been proposed as a more sensitive tool (10-16). In patients with various autoimmune diseases, we have previously shown that preserved basal adrenal function is associated with increase in basal ACTH levels and impairment of the adrenal response to very low ACTH doses (17). We, therefore, suspected that this hormonal profile would reflect some degree of early adrenal insufficiency (17). Based on this, the aim of the present study was to further support this hypothesis by testing the HPA response to classical provocative tests, such as hCRH and ITT (18-21); the working hypothesis was, in fact, an exaggerated corticotrope responsiveness to provocative stimuli, which would be predicted in the case of even subtle impairment of the negative glucocorticoid feedback action. In agreement with our previous study (17), herein, we show that this new cohort of autoimmune patients is connoted by mean basal ACTH levels higher than those recorded in NS, and absence of adrenal response to $0.06 \mu \mathrm{g}$ ACTH dose despite normal cortisol, aldosterone, and DHEA responses to the highest ACTH dose. The present results first demonstrate that autoimmune patients show clearcut enhancement of the corticotrope response to hCRH and even more to ITT, which is considered by far the most potent stimulus of the HPA axis $(18,19,21)$. Interestingly, autoimmune patients also showed a reduction in the cortisol response to hCRH, in agreement with other authors, who administered ovine CRH to the similar patients (22). The cortisol response to ITT in autoimmune patients was not significantly different from that in controls; this preserved cortisol response to ITT would, however, be explained by the very remarkable increase in the ACTH response to ITT. In fact, ITT is the most potent stimulus of the HPA axis and of ACTH secretion in particular $(18,19,21)$. In some way, the preserved cortisol response to ITT is reminiscent of the preserved response to the high ACTH dose. On the other hand, the reduction of the cortisol response to hCRH, which stimulates ACTH secretion far less than ITT, agrees with the impaired cortisol response to the very low ACTH dose. In all, the patients with autoimmune diseases display an HPA profile characterized by exaggerated ACTH secretion coupled with blunted adrenal 
responsiveness to non-maximal provocative stimuli. This functional HPA profile further points toward the hypothesis that some degree of subclinical primary adrenal insufficiency would be present in these patients. In fact, the increase in basal ACTH levels would represent the first adaptation devoted to maintaining adrenal function within the normal range in a condition of early impaired adrenal function. On the other hand, the normal adrenal response to the very high ACTH dose should not be a surprise given that it is extremely supra-maximal and has been found to be normal even in some patients with proven mild hypocortisolism (15, 23). The existence of some subclinical primary hypoadrenalism in our patients seems questioned by the lack of adrenal autoantibody positivity, as autoimmune patients with negative adrenal autoantibodies do not seem to develop overt hypocortisolism even after a long-term follow-up $(3,8)$. It remains that autoimmune patients show corticotrope hyperresponsiveness coupled with adrenal hyposensitivity to both low ACTH and non-maximal HPA stimulations. An alternative explanation of this HPA profile would come from considering that autoimmune patients have hyperactivation of immune system (24-27). In humans as well as in animals, a tight relationship between the immune system and the HPA axis is well recognized (24-26). Several inflammatory mediators induced by the autoimmune processes are known to stimulate HPA function
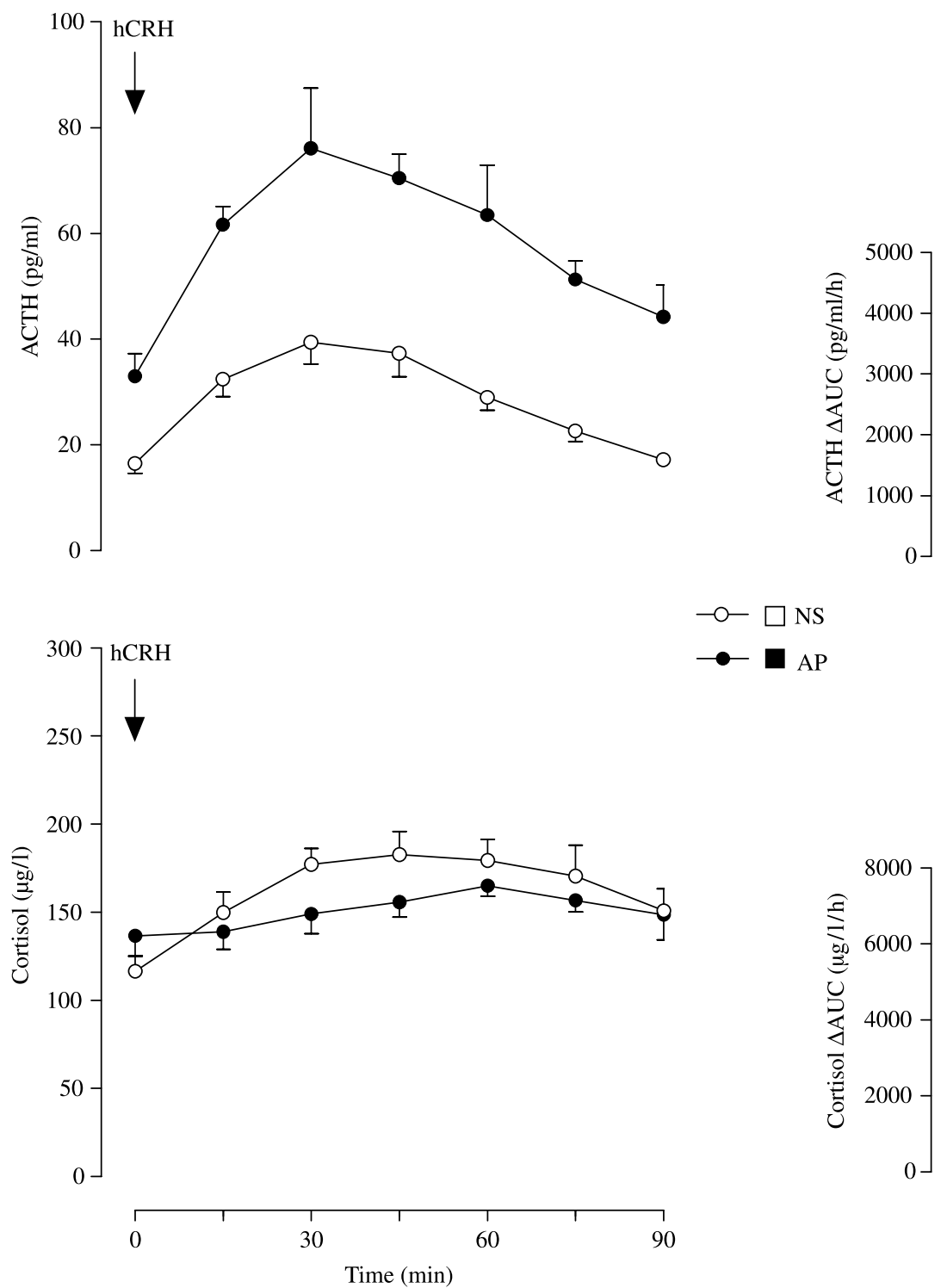


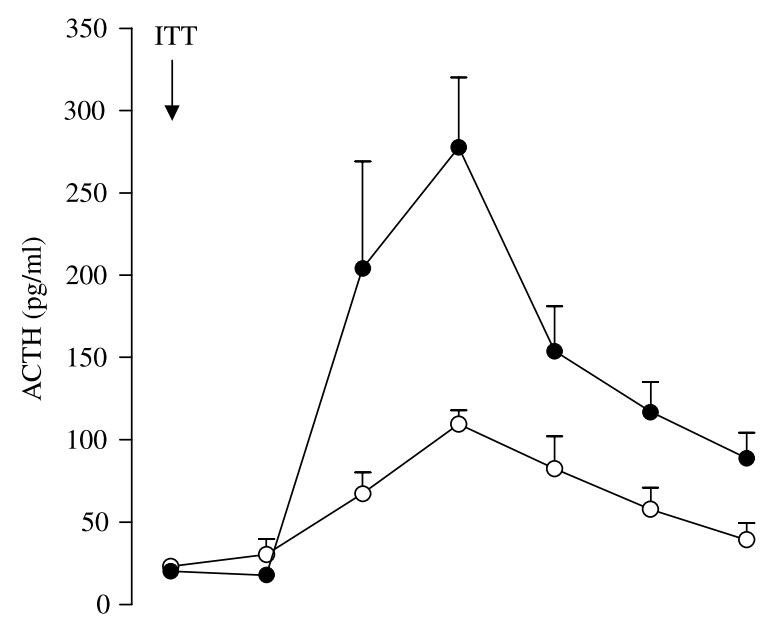

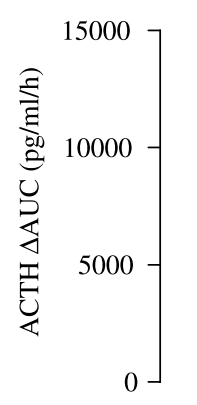

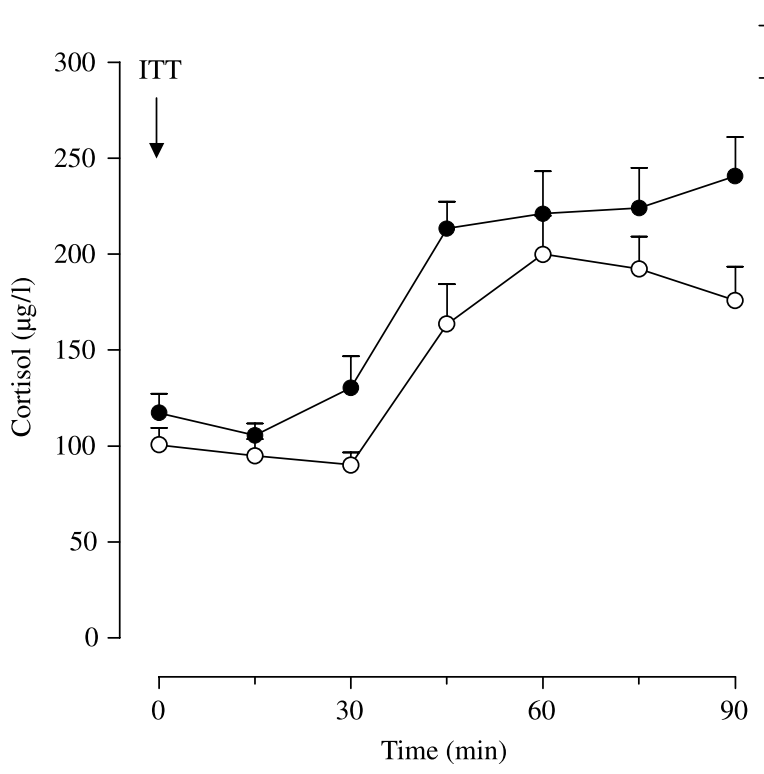

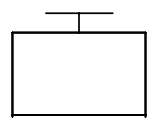

NS

$-\mathrm{O}-\square \mathrm{NS}$
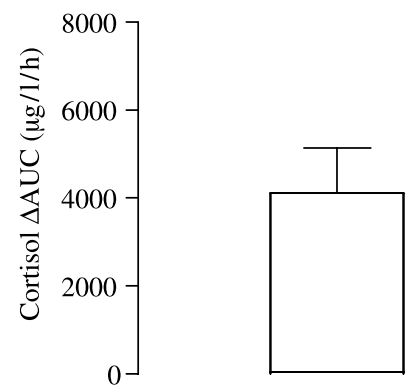

NS

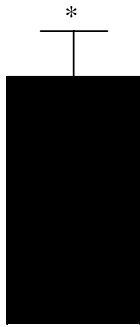

AP

Figure 3 Mean ( \pm S.E.M.) ACTH and cortisol levels and $\triangle$ AUCs after ITT $(0.1 \mathrm{Ul} / \mathrm{kg}$ i.v.) in patients with autoimmune diseases (AP) and normal subjects (NS). ${ }^{*} P<0.05$ vs NS.

acting at both pituitary and hypothalamic levels $(24-$ 27). This could explain basal and stimulated ACTH hypersecretion in autoimmune patients. Moreover, it may be hypothesized that chronic corticotrope hyperactivation induced by the autoimmune process, could have, at least partially, desensitized the adrenal gland to ACTH stimulation. In this respect, it cannot be excluded that lymphocytes or monocytes infiltrating the pituitary in patients with autoimmune diseases may secrete cytokines able to enhance, at least temporarily, corticotrope secretion by a paracrine mode (26). On the other hand, cytokines can also exert direct adrenal action; although stimulatory action has been reported by some authors (25), direct inhibitory effect of cytokines on adrenal function has also been reported (28). In the latter case, this would explain the blunted cortisol response associated with ACTH hypersecretion. The clinical implications coming out from this observation have to be demonstrated; however, these patients, in whom a normal adrenal function would be maintained by a corticotrope hypersecretion, should be carefully followed-up during conditions able to blunt corticotrope secretion, that is, medical treatments interfering with HPA function.

In conclusion, patients with autoimmune diseases without any symptoms and signs of hypoadrenalism show enhancement of both basal and stimulated corticotrope secretion coupled with a reduced adrenal sensitivity to low ACTH. This functional picture suggests that normal adrenal secretion is maintained due to corticotrope hyperfunction and would imply the existence of some subclinical primary hypoadrenalism. 


\section{Acknowledgements}

This study was supported by University of Turin and SMEM Foundation. The authors wish to thank Prof F Camanni for his support to this study and Dr A Bertagna, Mrs A Barberis and M Taliano for their skilful technical assistance.

\section{References}

1 Muir A \& Maclaren NK. Autoimmune disease of the adrenal glands, parathyroid glands, gonads and hypothalamic-pituitary axis. Endocrinology and Metabolism Clinics of North America 1991 20 619-644.

2 Riley WJ. Autoimmune polyglandular syndromes. Hormones Research 199238 9-15.

3 Betterle C, Dal Pra C, Mantero F \& Zanchetta R. Autoimmune adrenal insufficiency and autoimmune polyendocrine syndrome: autoantibodies, autoantigenes, and the applicability in diagnosis and disease prediction. Endocrine Reviews 200223 327-364.

4 Neufeld M, Maclaren NK \& Blizzard RM. Two types of autoimmune Addison's disease associated with different polyglandular autoimmune (PGA) syndromes. Medicine $198160355-362$.

5 De Bellis A, Bizzarro A, Rossi R, Paglionico VA, Criscuolo T, Lombardi G \& Bellastella A. Remission of subclinical adrenocortical failure in subjects with adrenal autoantibodies. Journal of Clinical Endocrinology and Metabolism 199376 1002-1007.

6 Betterle C, Volpato M, Rees Smith B, Furmaniak J, Chen S, Greggio NA, Sanzari M, Tedesco F, Pedini B, Boscaro M \& Presotto F. Adrenal cortex and steroid 21-hydroxylase autoantibodies in adult patients with organ-specific autoimmune diseases: markers of low progression to clinical Addison's disease. Journal of Clinical Endocrinology and Metabolism 199782 932-938.

7 Laureti S, De Bellis A, Muccitelli VI, Calcinaro F, Bizzarro A, Rossi R, Bellastella A, Santeusanio F \& Falorni A. Levels of adrenocortical autoantibodies correlate with the degree of adrenal dysfunction in subjects with preclinical Addison's disease. Journal of Clinical Endocrinology and Metabolism 199883 3507-3511.

8 Betterle C, Coco G \& Zanchetta R. Adrenal cortex autoantibodies in subjects with normal adrenal function Best practice and Research. Journal of Clinical Endocrinology and Metabolism 200519 85-99.

9 Ten S, New M \& Maclaren N. Clinical review 130: Addison's disease. Journal of Clinical Endocrinology and Metabolism 200186 2909-2922.

10 Oelkers W. Dose-response aspects in the clinical assessment of the hypothalamo-pituitary-adrenal axis, and the low-dose adrenocorticotropin test. European Journal of Endocrinology 1996 $13527-33$

11 Thaler LM \& Blevins LS Jr. The low dose (1 $\mu \mathrm{g})$ adrenocorticotropin stimulation test in the evaluation of patients with suspected central adrenal insufficiency. Journal of Clinical Endocrinology and Metabolism $1998 \mathbf{8 3} 2726-2729$.

12 Mayenknecht J, Diederich S, Bahr V, Plockinger U \& Oelkers W. Comparison of low and high dose corticotropin stimulation tests in patients with pituitary disease. Journal of Clinical Endocrinology and Metabolism $1998 \mathbf{8 3} 1558-1562$.

13 Patel L \& Clayton PE. Clinical usefulness of the low dose ACTH test. Journal of Endocrinological Investigation 199922 401-404.
14 Streeten DHP. Editorial: shortcomings in the low-dose (1 $\mu \mathrm{g})$ ACTH test for the diagnosis of ACTH deficiency states. Journal of Clinical Endocrinology and Metabolism 199984 835-837.

15 Laureti S, Arvat E, Candeloro P, Di Vito L, Ghigo E, Santeusanio F \& Falorni A. Low dose $(1 \mu \mathrm{g})$ ACTH test in the evaluation of adrenal dysfunction in pre-clinical Addison's disease. Clinical Endocrinology 200053 107-115.

16 Arvat E, DiVito L, Lanfranco F, Maccario M, Baffoni C, Rossetto R, Aimaretti G, Camanni F \& Ghigo E. Stimulatory effect of adrenocorticotropin on cortisol, aldosterone, and dehydroepiandrosterone secretion in normal humans: dose-response study. Journal of Clinical Endocrinology and Metabolism $2000 \mathbf{8 5}$ 3141-3146.

17 Giordano R, Pellegrino M, Oleandri S, Baldi M, Balbo M, Laureti S, Falorni A, Ghigo E \& Arvat E. Adrenal sensitivity to adrenocorticotropin 1-24 is reduced in patients with autoimmune polyglandular syndrome. Journal of Clinical Endocrinology and Metabolism 200489 675-680.

18 Greenwood FC \& Landon J. Assessment of hypothalamic pituitary function in endocrine disease. Journal of Clinical Pathology 196619 284-292.

19 Streeten DH, Anderson GH, Jr, Dalakos TG, Seeley D, Mallov JS, Eusebio R, Sunderlin FS, Badawy SZ \& King RB. Normal and abnormal function of the hypothalamic-pituitary-adrenocortical system in man. Endocrine Reviews 19845 371-394.

20 Orth D. Corticotropin-releasing factor hormone in humans. Endocrine Reviews 199213 164-191.

21 Fish HR, Chernow B \& O'Brian JT. Endocrine and neurophysiologic responses of the pituitary to insulin-induced hypoglycemia: a review. Metabolism 198635 763-780.

22 Boscaro M, Betterle C, Sonino N, Volpato M, Paoletta A \& Fallo F. Early adrenal hypofunction in patients with organ-specific autoantibodies and no clinical adrenal insufficiency. Journal of Clinical Endocrinology and Metabolism 199479 452-455.

23 Aimaretti G, Baffoni C, Di Vito L, Grottoli S, Gaia D, Gasco V, Giordano R, Zadik Z, Camanni F, Ghigo E \& Arvat E. Hypopituitaric patients with corticotropin insufficiency show marked impairment of the cortisol response to $\mathrm{ACTH}(1-24)$ independently of the duration of the disease. Journal of Endocrinological Investigation $20032649-55$.

24 Basedovsky HO \& Del Rey A. Immune-neuro-endocrine interactions: facts and hypotheses. Endocrine Reviews 199617 64-102.

25 Chrousos GP. The hypothalamic-pituitary-adrenal axis and immune-mediated inflammation. New England Journal of Medicine $19953321351-1362$.

26 Wick G, Hu Y, Schwarz S \& Kroemer G. Immunoendocrine communication via the hypothalamo-pituitary-adrenal axis in autoimmune diseases. Endocrine Reviews 199314 539-563.

27 Gaillard RC. Interaction between the hypothalamo-pituitaryadrenal axis and the immunological system. Annales d'endocrinologie 200162 155-163.

28 Ehrhart-Bornstein M, Hinson JP, Bornstein SR, Scherbaum WA \& Vinson GP. Intraadrenal interactions in the regulation of adrenocortical steroidogenesis. Endocrine Reviews 199819 101-143.

Received 23 March 2006

Accepted 31 May 2006 